\title{
Introduction: Theory, description, and analysis in affix order
}

\author{
Mark Aronoff · Stela Manova
}

Published online: 3 July 2010

(C) Springer Science+Business Media B.V. 2010

This is the second set of five articles selected from the workshop on affix ordering in typologically different languages that Stela Manova and Bogdan Szymanek organized at the 13th International Morphology Meeting in Vienna in February 2008. In the previous issue, as editors we set out the basic questions facing any attempt to model affix order, with special attention to the factors that may in principle be responsible for any particular order: essentially a typology of affix order (Manova and Aronoff 2010). We also reviewed the literature on affix order over the previous quarter century or so.

We will not repeat here what we said in our introduction to the last issue, although we believe that our remarks are still apt and accordingly direct the reader there for detailed scene-setting. In this issue we present five more articles on problems of affix order. In the previous issue, all five articles were devoted to hierarchical ordering in a single language. The current set is thematically more diverse, although each of the five articles again treats a single language.

Broadly speaking, though, we may say that all these articles share a common sensibility: that doing linguistics involves three distinct, though not always entirely separable enterprises: theory, description, and analysis. They are inseparable to the extent that one cannot describe or analyze data without some kind of (perhaps implicit) theory and every theory is constructed to deal with a particular type of phenomenon to be described and analyzed. What unites all the articles here is the principle that none of these three enterprises exists in a vacuum. We do not describe languages merely because of their contribution to linguistic theory or because we

M. Aronoff $(\bowtie)$

Stony Brook University, Stony Brook, NY, USA

e-mail: Mark.aronoff@stonybrook.edu

S. Manova

University of Vienna, Vienna, Austria

e-mail: stela.manova@univie.ac.at 
enjoy the excitement of linguistic analysis. Nor do we believe that the sole purpose of linguistic theory is its contribution to linguistic description. Rather each one is valuable in itself.

Natalia Korotkova and Yury Lander, in Deriving affix ordering in polysynthesis: evidence from Adyghe, present a reanalysis, based on their own field research, of verbal suffixes in Adyghe, a classic polysynthetic language of the Northwest Caucasian family that had previously been regarded as presenting a paradigm case of templatic morphology. Korotkova and Lander provide compelling evidence for the claim that the order of suffixes in this language is driven largely by semantic scope.

Rachel Nordlinger, in Verbal ordering in Murrinh-Patha: evidence for templates, demonstrates that, contrary to Adyghe, the verbal affix system of this non-PamaNyungan language of the Daly River region in the Northern Territory of Australia, in which every verb word contains both a lexical stem and a generic classifier stem, is not susceptible to a scope-base analysis but must rather be described by means of a template.

Dimitra Melissaropoulou and Angela Ralli, in Greek derivational structures: restrictions and constraints, analyze the order of derivational suffixes in Standard Modern Greek and some of its major varieties spoken in Asia Minor. They argue for suffix-driven selection over base-driven selection, along with both language-specific and language particular constraints. Certain of the dialects, for example, bar the cumulation of diminutives, which is perfectly acceptable in the standard language.

Roksolana Mykhaylyk, in Diachronic universals and morpheme order in the Ukrainian synthetic imperfective future, brings evidence from the history of Ukrainian to the old question of whether today's morphology is a reflection of yesterday's syntax. This history reveals that the relationship in question is rather more complex than this simple slogan might suggest and that the suffixal nature of the affix runs counter to the syntactic type of the language.

The last article, by Mark Aronoff and Zheng Xu, A Realization OptimalityTheoretic approach to affix order, is more theoretically oriented. Although it is devoted primarily to one language, Lezgian, it relies on data from Martin Haspelmath's 1993 grammar. The point of the article is to show how a theory that marries realizational morphology with optimality theory can accommodate many of the varieties of affix order that are discussed in the other articles on affix order in this and the previous issue.

Acknowledgements Once again, we take the opportunity to thank the many reviewers who helped us in selecting these articles. We also thank Ingo Plag for his infinite patience with us throughout the editorial process. Stela Manova and the workshop from which these articles emanated were supported by the Austrian Science Fund (FWF), grant V64-G03.

\section{References}

Haspelmath, M. (1993). A grammar of Lezgian. Berlin: Mouton de Gruyter.

Manova, S., \& Aronoff, M. (2010). Modeling affix order. Morphology, 20, 109-131. 